Bryn Mawr College

Scholarship, Research, and Creative Work at Bryn Mawr College

Graduate School of Social Work and Social

Graduate School of Social Work and Social

Research Faculty Research and Scholarship

Research

1999

\title{
Social Work Assessment: Case Theory Construction
}

Cynthia D. Bisman

Bryn Mawr College, cbisman@brynmawr.edu

Let us know how access to this document benefits you.

Follow this and additional works at: http://repository.brynmawr.edu/gsswsr_pubs

Part of the Social Work Commons

\section{Custom Citation}

Bisman, Cynthia D. "Social Work Assessment: Case Theory Construction." Families in Society 80 (1999): 240-246.

This paper is posted at Scholarship, Research, and Creative Work at Bryn Mawr College. http://repository.brynmawr.edu/gsswsr_pubs/17

For more information, please contact repository@brynmawr.edu. 


\title{
Social Work Assessment: Case Theory Construction
}

\author{
by Cynthia D. Bisman
}

\begin{abstract}
To intervene effectively, social workers need to make sense of clients and their situations. A case theory approach to assessment provides a framework to formulate assessments that are clear and directly related to the real-world problems clients present. Explaining the problem situation, case theory forms the foundation for selection of Intervention strategles and methods to achieve change. Bullding case theory requires practitioner ablittles to form concepts, relate concepts into propostions, develop hypotheses, and organize these into a coherent whole. Including case background information, observations and relevant professional literature, case theory presents an accurate and cogent comprehension of the client. Two case examples of depression illustrate the important relationshlp among concepts, empirlcal referents, propositions, general theortes, and intervention, highilighting how case theory guides practice.
\end{abstract}

AN OVERARCHING INQUIRY DIRECTS this article: How do social workers figure out what is going on with clients? Embedded within is another question: What is the point of this knowledge? I offer here a case theory framework for use by social workers to make sense of clients and their situations and connect that comprehension to treatment planning and intervention.

In social work, it is the assessment that determines the nature of the client's current situation at a particular point in time. Resulting in the product of a written assessment (variously called a psychosocial study, intake report, or social history, among other nomenclature) and entailing specific tasks such as observing and interviewing clients along with data gathering, the process of assessing is often ignored. Yet, without a clear framework for thinking about and engaging in the process of assessment, the products will be flawed and either useless to the social worker, or harmful to the client, or both.

Through gathering data that determines the relevant attributes of each case, social work assessment provides the "here and now" and how it got that way. A far more complex and significant process than data collection, assessment also incorporates the tasks of deciding which data to seek and how to organize it. Moreover, all practice components flow from the assessment that shapes the character of the professional relationship, impacts on communication methods and skills, directs social work intervention, determines measurements and data collection needs, and guides evaluation. As a joint activity by both the social worker and the client, assessment requires their mutual understanding and agreement. Engaged in a journey together, social workers and clients work to determine the nature of the problem causing the client difficulty so that they can change the situation.

Assessment was an effort by Mary Richmond to make the social work profession more scientific. In her Social Diagnosis (1917), she provides a lengthy and detailed method for obtaining social evidence, which was used by the social worker for understanding the client's difficulties and deciding "what course of procedure" to follow (p. 39). She states, "social diagnosis is the attempt to arrive at as exact a definition as possible of the social situation and personality of a given client. The gathering of evidence, or investigation, begins the process, the critical examination and comparison of evidence follows, and last come its interpretation and the definition of the social difficulty" (p. 62).

Social work has not yet reached a consensus on the structure and function of assessment. Some in the profession criticize a current trend to substitute psychodiagnosis for social work assessment by relying on prepackaged scales such as the DSM-IV (Mattaini \& Kirk, 1993; Abbott, 1988; Ikver \& Sze, 1987). Others, like Hudson (1990), call for heavy reliance on computers and stan-

Families in Society: The Journal of Contemporary Human Services

Copyright 1999 Families International, Inc. 
dardized scales, and Hopton (1998) reports on the use of psychological profiles in risk assessments.

\section{Importance of a Case Theory Approach to Assessment}

For social work assessments that are clear and directly related to the real-world problems that clients present, case theory provides a means of conceptualizing assessment and formulating assessments that are not only accurate and informative but also lead directly to relevant interventions. Case theory provides a set of ideas to understand and treat the symptoms or problems in functioning of one particular client (client may refer to an individual, family, group, community, or organization).

Consider the following situation facing Melissa, a social worker employed for two years by a child guidance center.

The eight-year-old client, Edith, is in second grade and has been residing with her maternal grandmother for the past year along with her ten-year-old sister and two older male cousins. Edith cries often, is uncommunicative at home, picks fights with children at school, and does poorly in school work. Records show that Edith's mother abused drugs and had several abusive relationships. Edith does not know ber father, who is incarcerated.

How does Melissa understand these facts? She looks closely at Edith's sad face and remembers information from her classes about attachment theory (Bowlby, 1977) that discontinuities of parenting can result in depression. Melissa has always been drawn to object relations theory (Winnicott, 1989), which offers her a way of understanding Edith's problems. Melissa decides that Edith has poor social relations with others because her split between good and bad was not resolved before she reached one year old and because of that she has low self-esteem resulting from lack of a supportive caregiver during infancy. Deciding that Edith is depressed, Melissa recommends weekly therapy sessions to help increase her selfesteem, utilizing play and supportive group therapy.

What do we think of Melissa's approach to this case and how she came to an understanding about Edith? Some may worry that Melissa was too quick with her diagnosis of depression, possibly neglecting other explanations for Edith's problematic behaviors. What if, instead of struggling with issues in her past, Edith is being abused now, possibly by her older male cousins? Or perhaps her symptoms are the result of her mother's drug use during pregnancy? Most of us can probably agree that Melissa needs a fuller understanding to be sure she is on the right track. More information is necessary about Edith's current home environment along with a learning assessment from the school and a current medical examination. If Edith is currently residing in an abusive situation, she continues to be at risk without intervention aimed at providing her with a safe environment. Likewise, should Edith have physiological problems making learning difficult for her, targeted help from the school at this early age could prove highly productive.

Missing in Melissa's assessment and intervention is a deliberative process of building an understanding that accurately explains her client's symptoms. A case theory approach to assessment provides a structure for social workers to follow in comprehending their clients. This framework emphasizes utilization of relevant contemporary literature and direct focus on the empirical evidence in the client's life. Conceptualizing assessment as case theory building enables practitioners to articulate what is happening with a particular client at one specific point in time and is essential to an intervention that is germane to that client and relevant to the presenting problem and context of the client situation.

Building case theory demands the knowledge about concepts and theory construction and the skills to relate concepts into propositions, develop hypotheses, and avoid deductive and inductive fallacies. Let us review these terms and then illustrate their use in formulating a case theory.

\section{Theory}

As Bisman and Hardcastle (1999) explain, pursuit of theory is to provide orderly explanations of the confusions in life experiences. In drawing patterns from observations to explain phenomena, different persons may explain the same events with a range of theories. The theory is not real but rather is the individual's attempt to explain real things. They further emphasize that available technologies and contemporary ideologies influence theories by discussing the contrast in theories about depression from the 1970s with those in the 1990s. Freudianism dominated the 1970 s explaining depression as a primarily psychological phenomenon. In the 1990 s pharmacology is the mode, viewing depression as a bio-chemical imbalance while gene research offers new ways to understand and explain the etiology of what was once considered solely a "mental" disorder. They predict more rapid 
shifts with increasing advances in technological knowledge.

Constructions by individuals to order events, theories offer logical conclusions based on presented relationships. Other than final proofs of logic and mathematics, which stem from stated premises and are not from or about the empirical world, theories do not offer universal laws bur rather present different levels of abstractness (some, such as Lakoff and Nunez, 1997, believe that even abstract mathematical concepts are based on human experience).

Perhaps one of the more elegant definitions of theories is offered by Karl Popper (1982) when he refers to "theories as human inventions - nets designed by us to catch the world" (p. 42), warning that "there is no absolute measure for the degree of approximation achieved for the coarseness or fineness of the net" (p. 47).

Whether grand, scientific, or case, theory is a systematically related set of propositions that explain and/or predict phenomena (Dubin, 1978, pp. 15-32; Lewis, 1982, pp. 18, 61-63; Reynolds, 1971, pp. 10-11, 87114). While theories are not inherently "real" or "hypothetical," their usefulness as constructions increase the more they can explain and predict. Theories range through levels of abstractness from grand theories that explain a lot of phenomenon to very concrete and circumstantial case theories that are locked in a specific time, place, and event. Freudian theory offers explanition of all human development and behavior and is an example of a grand theory. Good case theory provides understanding of the case, explaining why a particular client is behaving in a certain manner, laying the foundation for prediction of interventions necessary to accomplish the case objectives and case change.

\section{Concept Formation}

Case theory building requires specification and development of concepts - the fundamental units and building blocks of propositions and theories. For practitioners to understand the meaning of case theory, they must understand the theory's concepts. Ideas in the mind, concepts are the words or labels symbolizing the external things that the ideas represent. Just as we discussed with theories, concepts are not reality but represent a mental construction of reality.

The mental and empirical processes of developing and operationalizing concepts and relating the concepts to explain and predict things is theory building. Practi- tioners must relate concepts in case theory to each other. If the case theory building is faulty, interventions based on the theory are not likely to produce the intended results and may result in harm.

Understanding concept starts with three components illustrated in Table 1 below:

1. The idea or mental image and construction in the mind,

2. The words or labels symbolizing the idea, and

3. The external thing, phenomena, and empirical referents in the world represented by the labels.

\section{Table 1.}

\begin{tabular}{|l|l|l|}
\hline \multicolumn{1}{|c|}{ The ldea: } & \multicolumn{1}{|c|}{ Labelf } & \multicolumn{1}{|c|}{ The Referent } \\
\hline $\begin{array}{l}\text { The mental } \\
\text { picture and } \\
\text { construction of } \\
\text { come part of the } \\
\text { world. }\end{array}$ & $\begin{array}{l}\text { The word or } \\
\text { words represent- } \\
\text { ing the idea. }\end{array}$ & $\begin{array}{l}\text { The thing in the } \\
\text { world captured } \\
\text { by the idea. }\end{array}$ \\
\hline & Child abuse & \\
\hline
\end{tabular}

Conceptualization is the process of assigning words to ideas, abstractions, and constructions of empirical reality that have empirical references. Practitioners must not reify the concept by assuming that the idea is real or the only construction of reality. It is also important to develop the nominal definition and domain of the concept to distinguish empirical referents that fall within the idea from those that do not. Operational definitions that capture the idea are prerequisite to concepts that are usable in case theory.

\section{Propositions and Hypotheses}

Theories are composed of propositions, which are statements about the relationships among elements, concepts, or attributes of one or more concepts. Propositions allow us to understand concepts and relate and integrate them into theory. The task in building and reviewing theory, including case theory, is to find the "if-then" propositions that constitute the theory to explain the case and provide prediction for the appropriate intervention.

Hypotheses are propositions that are capable of empirical testing but as yet are untested. One function of research is to test and establish the validity of hypothetical propositions. Deduced from theory or induced from em-

'The following sections on theory draw from Bisman and Hardcastle, 1999, chapter four. 'Blumer's (1969) u'ork on symbolic interactionism influences these ideas. 
pirical generalizations and experiences, their purpose is to extend the explanatory and/or predictive capacity of theory or to explain empirical generalizations and experiences.

\section{Deduction and Induction}

Deduction is moving from a theory's general propositions to application of these propositions for the purpose of offering an explanation of the specific case.

The reasonableness of the hypothesis, the deduction,

General: (If) biological factors such as genetic family history and social factors such as social isolation contribute to depression. Specific: (If) individuals such as Mia Hanes have a genetic family history of depression and are socially isolated, (then) Mia Hanes' depression may be explained by and treated through physical and social factors such as medication and increased social support.

depends on (1) the validity or truthfulness of the general theoretical propositions from which the hypothesis was deduced, (2) whether the specific case falls within the class of cases covered by the theoretical propositions, and (3) its capacity to guide the intervention hypothesis for this specific case. Do biological theories and social isolation explain depression? Is Mia Hanes' depression explained by her biology and social isolation? If the answer to either is no, then the hypothesis that 'Mia Hanes' depression is explained by and treated with medication and social supports" is neither logically deduced nor empirically supported.

In induction, observations lead to analyses of patterns out of which propositions emerge to explain those patterns. Steps for observations necessary in inductions include: 1) examine a representative sample of socially isolated persons who also have a genetic family history of depression for patterns of the relationships between depression with social support and genetic family history; 2) explore whether increased social support and medication results in reduction of depression for these persons. If the pattern indicates that there is a reduction, then we can formulate the induction: medication and social support help reduce depression. For the above situation we are ready for the "if-then" proposition.

Specific: (If) examination of specific cases of persons with depression share factors other than depression such as social isolation and genetic family history and (if) persons without depression do not share these factors. General: (Then) the factors of social isolation and genetic family history are associated with depression.
Here, the reasonableness of the general proposition from the induction, depends on (1) representativeness of the sample of depressed and nondepressed persons and (2) presence of and observations of the factors within these samples. Do these persons share genetic family history and social isolation? Do other persons in the population share these factors who are not depressed? If the answer to either is no, then the hypothesis that social isolation and genetic family history are associated with depression is not empirically supported.

\section{Fallacies}

Deduction from general propositions to a specific case and induction from limited experience in research and practice to all cases can impede practice through deductive and inductive fallacies. Most social science theories describe characteristics of the general case or group. They are not laws covering all cases, a particular case, or even any case, within a class or group. One commits a deductive fallacy when assigning the attribute of a group or class described by a general theory to a specific case within the class, but the case does not contain the attribute. Assuming that a trait of all adults who were abused as children is to abuse children, and then inferring a particular client who was abused as a child is abusing her children, is commission of a deductive fallacy.

Conversely, an inductive fallacy is wrongly assuming that the trait of an individual case within a group applies to all or any other case in that group, if they do not share the trait. Social workers over relying on practice wisdom, limited case experience, or research with inappropriate, inadequate, and unrepresentative samples in building case theory are likely to commit inductive fallacies. For example, a social worker is treating four clients who share a common problem - they each have bulimia. In obtaining family history, this worker discovers that each client was an incest victim. Concluding that incest causes bulimia, the social worker ascribes a trait, "incest victim," to a group, "those who have bulimia." In committing this inductive fallacy, the practitioner erroneously generalizes from the four specific cases to a larger group. Incest is not a trait of all those who have bulimia nor do most incest victims become bulimic. The few cases do not adequately represent the larger group.

\section{Case Theory Construction in Practice}

If successful, case theory accounts for the phenomena of this one case, but does not prove the general theo- 
ry for classes of persons. A construction of social reality, case theory is the meaning attached by the social worker to the client's narrative and other gathered information, leading to shared construction of a new reality for the client, reflected in the intervention.

\section{General and Case Theories}

Practice without case theory leaves practitioners relying on the general theories of behavior, which are usually too broad to be of much use in adequately understanding a specific client or are dependent on loosely formed hunches that may relate more to their own instincts than to empirical data. Faulty case theories are also harmful. Drawing from the wrong general theories, they provide information that is not relevant and may even be dangerous to the client.

Social, psychological, and behavioral theories including systems and exchange theory, psychodynamic, operant, social learning, and cognitive theories do inform case theories. Nevertheless, they are quite different. These conceptual models are nomothetic, which means they apply to groups of persons while case theories are idiographic. As Bisman states, "By definition, if the case theory fits this individual case, it will totally fit no other client situation" (1994, p. 117). A central feature of case theories is their use of these general theories to provide support from a wide body of professional research and scholarship.

Case theory determines which of these general theories or professional literature to choose. Rather than one particular theoretical model driving all practice decisions, a case theory approach requires knowledge of multiple theories and the ability to utilize a framework that best relates to the circumstances of a specific client. This may be clearer when we think of a medical situation. We would not expect a specialist in gastrointestinal disorders to diagnose all problems as intestinal, but rather to rely on a thorough medical examination and remain open to a range of explanations for the patient's problems. Prescribing medication for pain resulting from gastro reflux can result in great (even deadly) harm if the patient's pain is instead from angina and heart attacks go untreated.

Furthermore, for fully developed and valid social work case theories that adequately address the breadth of the social work domain, social workers need to use biopsycho-social models, including biological information of genetic content and physical attributes, psychological data covering the intrapsychic and personality factors, and the social information about range and type of community and social supports and resources with their availability to the client.
These differ from the (1) bio-psycho-medical theories of human behavior that present behavior as the result of the individual's biological and intrapsychic content, whether due to genetic content or early socialization, (2) educational theories that view behavior and management of social relations and the social environment as learned or conditioned, and (3) psycho-social theories that interpret behavior as a function of the individual's psychological content in interaction with the social context.

It is not unusual, however, for practitioners to skip the process of formulating such an understanding for each of their clients and instead solely rely on general concepts, such as depression or alcoholism. A basic assumption, however, in utilization of diagnostic categories is a shared understanding of these phenomena. Yet as we discussed earlier, these concepts are not real but rather refer to empirical events. Accordingly, knowledge of these specific circumstances is necessary to understand each individual client's depression or substance abuse in order to plan an intervention that relates to that particular client's real-life circumstances. This is particularly important because there are many general theories explanatory of concepts such as depression and alcohol abuse. Moreover, with increasing reliance on the growing number of DSM IV categories, it is essential to clarify the meaning of the diagnosis. Just as physicians must provide specificity when diagnosing cancer or heart disease, social workers must identify the attributes of their diagnoses.

\section{Case Example and Case Theory}

Let us consider another example and examine the social worker's approach to building a case theory.

Based at an urban community mental health center which provides services to any residents, the social worker, Janet, meets with Rosie, a forty-five-year-old Latino woman. Currently unemployed, Rosie completed tenth grade and has held various jobs, usually as a sales clerk. She lives with her twenty-five-year-old daughter, has little interaction with her family, and keeps very few friends. Rosie came into the session complaining that she feels sad and has little energy. When Janet pushes for specificity, she learns that Rosie often sits around the house all day doing nothing, sleeps about twelve to fourteen hours, watches TV about six to eight hours, and is losing weight because she does not eat very much. Janet asks how long she has felt this way and learns that Rosie has had these bad feelings on and off since her early teens, when she used to think of killing herself. These thoughts often alternated with great bursts of energy when Rosie felt wonderful. Asking how it is that she is 
now asking for help, she learns Rosie feels worse since testing positive for HIV, three months ago.

Janet formulates the following case theory:

Rosie's recent $H I V$ diagnosis is exacerbating her long term social isolation and possible clinical depression. Goldstein (1995) and Jue (1994), indicate that stigma from AIDS often socially isolates these patients, while Mancoske (1996) points to their greater risk of suicide. Individuals need an active energy exchange with others as Greene (1991) explains in her discussion of systems theory, and for a long time Rosie has had no person with whom she can talk openly. Her long history of severe mood swings suggests bipolar disorder. Evidence supports a biological basis for treatment of depression (Sperry, 1995). Jensen (1994) points to a psychosocial perspective combined with a biological perspective.

Because she knows we can use the concept of depression to describe different conditions, Janet identifies the empirical indicators relevant for each client labeled as depressed. The empirical behaviors for Rosie include the following problems: sleeps an average of thirteen hours per day, shows a decrease in appetite, has severe mood swings, and an overall lack of functioning with extensive

Developed from data collection and observations, case theory presents social workers' understanding of a particular client's problematic condition at a specific point in time.

periods of sitting around and watching television.

Propositions in Janet's case theory pose a relationship between social isolation, illness, biology, and depression. Janet's hypothesis is a deduction that Rosie's symptoms are explained by her biology, social isolation, and disease. Correspondingly, Janet refers to general theories of systems, biological and psychological, and social explanations for understanding depression and the psychosocial effects of AIDS.
Emerging from this case theory, Janet's intervention includes both increasing social supports and a medical consult to consider pharmacology for the possible bipolar disorder. Focus on just AIDS, or only the social isolation, or solely the clinical depression ignores important variables. Janet is aware that any of these narrow interventions is potentially harmful to Rosie.

When we compare Janet's approach to understanding Rosie with our earlier example of Melissa, we can see the enhanced practice by Janet who is able to directly link this understanding to her intervention based on concrete evidence. The clear statement of her case theory's propositions and hypotheses and identification of the general theories she uses prevent fallacies in her thinking. By broadly basing her case theory to incorporate multiple hypotheses, she logically draws from a range of general theories resulting in a plan of intervention that addresses the breadth of social work practice by including biological, psychological, and social factors.

\section{Summary}

In response to the initial questions of how social workers make sense of clients and what they do with that information, we have examined a case theory approach to social work assessment requiring comprehension of theory, specification of concepts, and development of propositions and hypotheses. Emphasis is on the linkages between building a theory of the case with accurate client assessments and relevant subsequent practice interventions. While recognizing the importance of case theory constructions by practitioners, this framework also distinguishes case theory from those general theories found in the literature.

Case theory, like all theory, is explanation of phenomena. Idiographic, case theory applies only to a specific case and is distinct from social and behavioral theories, which are nomothetic and apply generally to groups of persons. Developed from data collection and observations, case theory presents social workers' understanding of a particular client's problematic condition at a specific point in time. As Florence Hollis (1970) stressed in her development of the psychosocial approach, the purpose of assessment is to develop the basis for treating each client as a separate individual. Addressing specific empirical events, the test of the case theory is the extent to which it explains this unique client, accounts for the phenomena, and guides a successful intervention. Case theory connects this client's past to the present and future in order 
to project a future set of events - the change in the client's presenting problems (Bisman, 1994).

Social workers must consider and confront both social context and individual content of behavior and accordingly rely on bio-psycho-social theories where behavior is a function of the individual client's biological and psychological content and the social context - the social work domain.

Social work practice involves using and testing theories. To formulate their assessments, social work practitioners require theory-building knowledge and skills. Building case theory requires practitioner abilities to form concepts, relate concepts into propositions, develop hypotheses, and organize these into a coherent whole. From case theory's coherent explanation of the empirical referents and reference to general theories and wide professional knowledge, come selection of intervention strategies with methods to change the presenting problems. Including client background information and pertinent professional literature, case theory presents a cogent and valid comprehension of the client, a prerequisite for appropriate interventions that are helpful to clients.

\section{References}

Abbott, A. (1988). The system of professions: An essay on the division of expert labor. Chicago: University of Chicago Press.

Bisman, C. D. (1994). Social work practice: Cases and principles. Pacific Grove, CA: Brooks/Cole.

Bisman, C., \& Hardcastle, D. (1999). Integrating research into practice: A model for effective social work. Pacific Grove, CA: Brooks/Cole.

Blumer, H. (1969). Symbolic interactionism. Englewood Cliffs, NJ: Prentice-Hall.

Bowlby, J. (1977). The making and breaking of affectional bonds. British Journal of Psychiatry, 130, 201-10.

Dubin, R. (1978). Theory building. New York: Free Press.

Goldstein, E. G. (1995). Working with persons with AIDS. In E. Goldman (Ed.), Ego psychology and social work practice (pp. 274. 281). New York: Free Press.

Greene, R. R. (1991). General systems theory. In R.R. Greene \& P. H. Ehross (Eds.), Human behavior and social work practice, (pp. 227-259). New York: Aldine De Gruyter.

Hollis, F. (1970). The psychosocial approach to the practice of casework. In R. Roberts \& R. Nee (Eds.), Theories of social casework, (pp. 33-76). Chicago: University of Chicago Press.

Hopton, J. (1998). Risk assessment using psychological profiles techniques: An evaluation of possibilities. The British Journal of Social Work, 28(2), 247-261.

Hudson, W. W. (1990). Computer based clinical practice. In L. VidekaSherman \& W. J. Reid (Eds.), Advances in clinical social work research (pp. 105-117). Silver Spring, MD: NASW Press.

Ikver, B., \& Sze, W. (1987). Social work and the psychiatric nosology of schizophrenia. Social Casework, 68, 131-139.
Jensen, C. (1994). Psychosocial treatment of depression in women: Nine single-subject evaluations. Research on Social Work Practice, 4, 267-282.

Jue, S. (1994). Psychosocial issues of AIDS long-term survivors. Families in Society, 75(6), 324-332.

Lakoff, G., \& Nunez, R. (1997). In L. English (Ed.), Mathematical reasoning: Analogies, metaphors, and images. Erlbaum.

Lewis, H. (1982). The intellectual base of social work practice. New York: Haworth Press.

Mancoske, R. (1996). HIV/AIDS and suicide: Further precautions. Social Work, 3, 325-326.

Mattaini, M., \& Kirk, S. A. (1993), Points and viewpoints: Misdiagnosing assessment. Social Work, 38, 231-233.

Popper, K. (1982). The open universe: An argument for indeterminism. (From the postscript to The Logic of Scientific Discovery, originally published as Logik der Forschung in 1935 and revised, 1959). Totowa, NJ: Rowman \& Littlefield.

Reynolds, P. (1971). A primer in theory construction. New York: Macmillan.

Richmond, M. (1917). Social diagnosis. New York: Russell Sage Foundation.

Sperry, L. (1995). Psychopharmacology and psychotherapy: Strategies for maximum treatment outcomes. New York: Bruner Mazel.

Winnicott, D. W. (1989). Psychoanalytic explorations. Cambridge, MA: Harvard University Press.

Cynthia D. Bisman is associate professor, Bryn Mawr College, Graduate School of Social Work, Bryn Mawr, PA.

Author's note: The author acknowledges the following Bryn Mawr MSS students for their case material: Jacqueline Stahl and Janine Wettstone.

Original manuscript received: July 1,1998

Revision received December 28, 1998

Accepted: January 1, 1999 